\title{
Formação e mudança em Artes Visuais na contemporaneidade
}

\section{Formation and change in contemporary Visual Arts}

\author{
Umbelina Barreto \\ Universidade Federal do Rio Grande do Sul
}

\begin{abstract}
Resumo
O artigo refere-se a uma investigação que emerge dos processos de institucionalização da Arte na Educação Brasileira. As mudanças curriculares no Curso de Graduação em Artes da Universidade Federal do Rio Grande do Sul são elencadas e, nessa busca, faz-se convergir os lugares da experiência formativa ao se perseguir os fundamentos que possibilitam novas orientações na Educação das Artes na Contemporaneidade. Utiliza-se os conceitos de mudança e permanência à luz da Teoria do Conhecimento de Maturana e Varella (1984). E utiliza-se a pluralização da comunicação trazida por Santaella (2010) como uma definição apropriada da visão de mundo contemporânea. Dentre os lugares da mudança enfatiza-se o lugar do Desenho a partir da perda de seu lugar canônico dentro da Arte. E, por fim, traça-se um percurso didático do Desenho que possa contribuir para a emergência de um sujeito autônomo, com uma atitude criadora e crítica, e que se encontra inserido na atual Sociedade de Informação e Conhecimento.
\end{abstract}

\section{Palavras-chave}

Institucionalização da Arte, experiência formativa do Curso de Artes da UFRGS, mudança e permanência, convergências, percurso didático do Desenho.

\begin{abstract}
The article refers to an investigation that emerges from the processes of institutionalization of Arts in Brazilian Education. The curricular changes in the undergraduate course of Arts at Federal University of Rio Grande do Sul are listed and, in this search, places of formative experience are converged when chasing the fundamentals that enable new guidelines for Arts Education in the contemporaneity. The concepts used include those of change and permanence in the light of Theory of Knowledge by Maturana and Varela (1984). Also the pluralization of communication brought by Santaella (2010) is used as a definition appropriated from the contemporary worldview. Among the places of change, the place of Drawing is emphasized considering the loss of its canonical place in the Arts. And, finally, a didactic route in Drawing is constructed so that teaching contributes to the emergence of an autonomous subject who has a creative and critical attitude and is inserted in the current Society of Information and Knowledge.
\end{abstract}

\section{Keywords}

Arts institutionalization, formative experience of the Arts course at UFRGS, change and permanence, convergences, didactic route of Drawing.

\section{De onde surgem os fundamentos?}

Investigar os fundamentos que norteiam a Educação das Artes na Contemporaneidade pode envolver também os lugares da experiência formativa definida em contextos institucionais emergentes dos Sistemas de Ensino de um país. Dentre estes contextos, no Brasil, considera-se importante assinalar a passagem que marca a mudança de nomenclatura da Área de Arte, finalmente reconhecida como uma Área de Conhecimento. A partir das Diretrizes Curriculares Nacionais, advindas da sistematização da Lei de Diretrizes e Bases da Educação Nacional Brasileira, de 1996, a Área de Artes Plásticas,

Revista Digital do LAV - Santa Maria - vol. 8, n. 2, p. 104 - 117. - mai./ago. 2015 ISSN 1983 - 7348 http://dx.doi.org/10.5902/1983734819867 
correspondente aos tradicionais processos artísticos, foi redefinida, principalmente, ao abarcar as novas tecnologias, sendo renomeada como Área de Artes Visuais.

Nesse sentido, focalizar o contexto que envolva as mudanças curriculares do Curso de Artes, que passou de Curso de Graduação em Artes Plásticas a Curso de Graduação em Artes Visuais, do Instituto de Artes da Universidade Federal do Rio Grande do Sul, pode trazer contribuições significativas na determinação de um elenco que fundamenta e norteia o ensino da Arte na contemporaneidade.

Ao se considerar as mudanças que foram sendo implementadas no percurso didáticopedagógico do ensino da Arte na contemporaneidade, desde a determinação da obrigatoriedade das Artes na Escola Básica, a princípio como atividade e, posteriormente, como componente curricular, até a atualidade, em que as Artes passaram a fazer parte do Ensino Médio, e estão inseridas na área de Linguagens, Códigos e suas Tecnologias, verifica-se que estas mudanças convergem para as mudanças que foram ocorrendo no universo da Arte e, também no universo da Educação, as quais marcam a segunda metade do século XX e o início do século XXI.

Este artigo, ao se voltar sobre a especificidade da formação superior em Artes Visuais na atualidade, possibilita, simultaneamente, uma reflexão sobre os fundamentos da Educação das Artes na contemporaneidade, no sentido em que tenta-se esboçar alguns apontamentos para a elaboração de uma matriz de referência que propicie o desenvolvimento de percursos didáticos, principalmente, no que se refere a linguagem do Desenho, envolvendo dinâmicas do pensamento e da ação que possam contemplar a complexidade das transformações do mundo atual.

No texto, parte-se do contexto educacional brasileiro, considerando as mudanças sucedidas no mundo, e as que se estão a suceder, tanto na Sociedade como no Conhecimento e na Arte. Mais especificamente, as mudanças que se sucedem no mundo são focalizadas a partir da convergência com as transformações internas operadas no universo artístico, e com as transformações externas, determinadas pela crescente institucionalização da área de Artes Visuais, definida hoje como uma área de Conhecimento, ao lado das demais áreas de Conhecimento, tal como as Ciências Sociais ou as Ciências Biológicas, dentre outras tantas áreas em que se estrutura e diferencia a complexidade do Conhecimento atual.

É importante chamar a atenção para o fato que o processo de institucionalização de "novas" áreas de Conhecimento deu-se como uma expansão da especialização do Conhecimento, articulado a um ensino totalmente disciplinarizado, que caracterizou o século $X X$. Entretanto, sublinha-se que, concomitantemente, ocorreu a geração e expansão de diversas formas de articular e relacionar disciplinas, em processos inter, multi e trans disciplinares, ainda no século $X X$, que, de certa forma, surgiram para atender às transformações do Conhecimento e da Sociedade do século XXI, que, na época, era percebida como uma "Sociedade do futuro".

Examina-se, em um primeiro momento, a possibilidade de vislumbrar os novos lugares educativos que vão sendo instituídos no mundo contemporâneo e a forma como estes lugares agregam e, simultaneamente, rejeitam a Arte como constitutiva do processo de desenvolvimento da Educação, e, consequentemente, do processo de desenvolvimento da aprendizagem, influenciando diretamente nos processos de escolarização em que se quer fazer emergir um sujeito autônomo, com uma atitude criadora e, simultaneamente, crítica,

Revista Digital do LAV - Santa Maria - vol. 8, n. 2, p. 104 - 117. - mai./ago. 2015 ISSN 1983 - 7348 http://dx.doi.org/10.5902/1983734819867 
e que se encontra, como todos nós, inserido na atual Sociedade de Informação e Conhecimento.

Constata-se que a Área de Artes Visuais se encontra diretamente ligada às mudanças que envolvem o uso das tecnologias, que caracterizam tão bem essa Sociedade de Informação e Conhecimento. Seja no sentido da proliferação do uso de novas tecnologias, pela facilidade do acesso e operacionalização de equipamentos e dispositivos, em interfaces que se apresentam constituídas por imagens na forma de mapas ou outra forma visual; seja pela estetização do cotidiano, em que as relações interpessoais passam a ser, frequentemente, mediadas por imagens capturadas e guardadas em equipamentos portáveis, e que estão acessíveis a todos, ou mesmo pela constante exposição de pessoas transformadas em imagens de um universo virtual. Principalmente, ao se constatar que desse universo virtual foram eliminadas as dicotomias de público/privado, bem como as dicotomias entre interior/exterior, além de outras dicotomias que fazem parte de nosso universo, e que ainda são significativas, por organizar e constituir duas partes distintas, opostas e complementares de um mesmo corpo, considerando o corpo de um único indivíduo ou o corpo de um conjunto de indivíduos, tal como um corpo social.

Vive-se hoje em um aparente estado de submersão no universo virtual, definido por um espaço multiplicado exponencialmente pela imagem, e que redefine, reiteradamente, a nossa relação com o mundo. Ao se estar submerso no virtual, sofre-se uma espécie de escaneamento constante, como uma invasão desejada/não desejada, interna/externa, sendo que o mapa resultante desse esquadrinhamento interfere em todos os lugares, atuando diretamente nas escolhas que se faz, e, consequentemente, nas ações de todos nós.

Santaella (2010) menciona três momentos fundamentais, da genealogia da técnica, ligando-os à dominação na história do Ocidente, o momento cartesiano, o momento kantiano e o momento nietzschiano. Na discussão que a autora faz do humano e póshumano, ao apresentar um sentido negativo da tecnologia, enfatiza o primeiro momento como dominação, o segundo como uma dominação posta rumo ao progresso do projeto moderno, e, no terceiro como a dominação com um fim em si mesmo, fazendo da técnica uma finalidade em si mesma. Verifica-se que a visão da tecnologia, por este viés na discussão do negativo trazido pela autora, apresenta-se como um rapto da natureza. Esta forma de abordar a visão negativa da tecnologia em relação a natureza humana, faz lembrar de dois mitos fundantes da história do Ocidente, do mito Grego do Rapto de Europa, que funda a relação entre os deuses e a natureza humana, bem como do mito Romano do Rapto das Sabinas, dito como fundante da primeira geração de romanos livres, filhos das primeiras relações matrimoniais de romanos com mulheres.

Frente a esse panorama, criticado e também defendido por muitos, em que o universo virtual, intermediado pela arte, tem contagiado recursivamente a realidade em que se vive, busca-se ainda uma brecha, em que ainda seja possível trabalhar com a formação artística, especificamente com o Desenho e a Linguagem Visual. E, nessa busca, tenta-se engendrar o surgimento de um novo sujeito que possa ultrapassar as limitações que são impostas com uma aparência de espaço ilimitado, em uma atualidade que, com frequência, escapa, pois se desconstrói e volta a se reconstruir iterativamente, permanecendo, permanentemente, em desconstrução e em crise, sem que seja dada concretamente a partilha dessa nova realidade.

\section{Dos lugares da experiência formativa}

Revista Digital do LAV - Santa Maria - vol. 8, n. 2, p. 104 - 117. - mai./ago. 2015 ISSN 1983 - 7348 http://dx.doi.org/10.5902/1983734819867 
Toma-se como referência, nessa reflexão que se está a construir, a realidade brasileira de formação do profissional de Artes Visuais no contexto de um Curso de Graduação que atende às Diretrizes Curriculares Nacionais (DCN-Artes Visuais). Nessas diretrizes, que estão definidas na Resolução CNE/CES 1/2009, sistematizada a partir da Lei de Diretrizes e Bases da Educação Nacional de 1996, Lei 9394 de dezembro de 1996, e que foi publicada no Diário Oficial da União, Brasília, em 19 de janeiro de 2009, se define a realização de um estreito diálogo entre a formação do artista, através da formação do Bacharel em Artes Visuais, e a formação do Professor de Artes Visuais, através da formação do Licenciado em Artes Visuais.

No documento das DCN-Artes Visuais é preconizada uma arquitetura curricular única, que abarca distintas estruturas curriculares, com diferentes planos de estudo em dois projetos pedagógicos independentes, um para o Curso de Licenciatura e outro para o Curso de Bacharelado, enfatizando, tanto a articulação entre os dois cursos, como as finalidades específicas de cada um. Nessa arquitetura curricular, verifica-se a emergência de uma ênfase em processos de criação que perpassam a formação do artista e a formação do professor.

Observa-se que, a partir dessa articulação dos dois cursos, na formação artística do Bacharel em Artes Visuais ocorre um permanente deslocamento relacionado ao exercício profissional, o que acarreta, reiteradamente, a busca por uma dupla formação, definindo o regresso deste profissional à universidade, depois de diplomado, com o objetivo de fazer uma formação em Licenciatura, o que possibilita também o seu exercício profissional como professor de Artes Visuais na Escola Básica.

Esta realidade brasileira, de certa forma, não é tão recente, pois tem sido confirmada, com algumas variações e inversões, desde o regime de exceção, durante a ditadura, através da Lei de Diretrizes e Bases da Educação Nacional de 1971, Lei 5692/71, anterior à legislação atual. Nesta Lei foi instituída a obrigatoriedade da Educação Artística no $1^{\circ}$ e $2 .{ }^{\circ}$ Graus, caracterizando-a como uma prática a ser controlada em um governo militar e em uma economia voltada, essencialmente, para o desenvolvimento científico e tecnológico.

A sistematização que se seguiu a partir da Lei de 1971, definindo componentes curriculares obrigatórios nos Cursos Superiores de Formação de Professores de Educação Artística, possibilitou certa uniformização nacional, principalmente, nos novos cursos que surgiram para atender a obrigatoriedade preconizada. Entretanto, também possibilitou a continuidade de características específicas em cursos do Ensino Superior do âmbito federal, que fizeram somente adaptações em seus currículos para atender à nova legislação.

Este é o caso do Curso Superior de Artes Plásticas do Instituto de Artes da Universidade Federal do Rio Grande do Sul, que foi criado no início do século XX, como Instituto Livre de Belas Artes, passando a Instituto de Belas Artes da Universidade Estadual do Rio Grande do Sul, sendo federalizado na década de 50, quando a Universidade Estadual do Rio Grande do Sul passou a fazer parte do Sistema Federal de Educação, como Universidade Federal do Rio Grande do Sul.

Dentro deste contexto, pode-se levantar alguns fundamentos que definem a formação superior em Artes Plásticas até a sua substituição por uma formação superior em Artes Visuais, em uma mudança definida pela legislação atual.

A formação em Artes Plásticas determinando uma Formação Superior em Desenho e Plástica com declarada ênfase em Artes Plásticas, e com habilitação em Educação Artística,

Revista Digital do LAV - Santa Maria - vol. 8, n. 2, p. 104 - 117. - mai./ago. 2015 ISSN 1983 - 7348 http://dx.doi.org/10.5902/1983734819867 
para dar conta da "Educação Artística", definida na Lei de 1971, caracterizou-se por um currículo com fundamentos modernistas, mirando-se, de forma direta no modelo da Escola Bauhaus, escola alemã do início do século XX, fundada em 1919, na República de Weimar, por Walter Gropius, e fechada em 1933 sob a pressão do nacional-socialismo alemão.

Este modelo de escola, de vida muito breve, mas intensa, foi analisado por Rainer Wick (1989) como um "entroncamento de correntes aparentemente contrárias mantidas em equilíbrio tenso e produtivo", tendo sido perpassada por um modelo da Pedagogia Reformista, a partir de 1923, ensejando a reconstrução da unidade da esfera artística e cultural com a reintegração da arte na vida, ao utilizar a arte como instrumento de regeneração cultural e social.

Ao se pensar na relação entre Cultura, Sociedade e Conhecimento como um dispositivo topológico, ou seja, como um processo de construção da experiência envolvendo esses três campos, pode-se definir uma sintonia entre a Pedagogia Reformista da Bauhaus (1923) e a Pedagogia Progressista de Dewey (1934), principalmente para impulsionar a relação entre o pensamento e a ação, articulando a completude e a incompletude que caracteriza a concretude da experiência (Barreto, 2008).

O Curso de Artes Plásticas do Instituto de Artes da UFRGS, definido por fundamentos modernistas formava na década de 70, o Graduado em Artes Plásticas como um especialista em uma das diversas Habilitações Artísticas oferecidas, tal como Pintura, Escultura, Gravura e Cerâmica, e também formava o Licenciado em Educação Artística na Habilitação Desenho e Plástica. Posteriormente, o curso foi redefinido como Bacharelado em Artes Plásticas, com uma das Habilitações Artísticas escolhida pelo aluno, e Licenciatura em Educação Artística, Habilitação Artes Plásticas.

No Curso de Graduação em Artes Plásticas, com uma duração de 04 (quatro) anos, a estrutura curricular estava definida em 05 (cinco) Habilitações com disciplinas totalmente compartilhadas nos 02 (dois) primeiros anos. De um lado, tinha-se as Habilitações relacionadas à formação do artista, e, de outro, tinha-se a Habilitação relacionada à formação do professor. Nos dois últimos anos, nas Habilitações Artísticas se aprofundava o Conhecimento da Arte em atelieres específicos em disciplinas oferecidas no Instituto de Artes, e, na Habilitação em Educação Artística, se desenvolvia o Conhecimento Pedagógico necessário para o exercício da função de professor, em disciplinas oferecidas na Faculdade de Educação.

Na metade do percurso de formação do professor, era possibilitado aos alunos realizar um estágio na Escolinha de Artes dos ex-alunos do Instituto de Artes da UFRGS, escola com uma orientação voltada, prioritariamente, para a livre expressão, evidenciando a espontaneidade infantil. Desse modo, os alunos eram levados de um polo ao outro em sua formação, deslocando-se dos rígidos referenciais cognitivo-matemáticos presentes em grande parte das disciplinas cursadas, principalmente no Desenho, até a anulação total desses referenciais, na observação de manifestações das crianças centradas, exclusivamente, no sentimento.

O curso era perpassado pelo ensino cronológico/linear da História da Arte, ampliado com disciplinas técnicas relacionadas ao Design, denominadas de Técnicas de Composição Artística, e estruturado em um eixo artístico fundamentado nas disciplinas de Desenho. 0 conhecimento, relativo a área de Desenho, era desenvolvido em uma carga horária significativa, abrangendo várias disciplinas que perpassavam o conhecimento técnico, o conhecimento perceptivo, o conhecimento formal e o conhecimento instrumental,

Revista Digital do LAV - Santa Maria - vol. 8, n. 2, p. 104 - 117. - mai./ago. 2015 ISSN 1983 - 7348 http://dx.doi.org/10.5902/1983734819867 
ensejando ou encaminhando a articulação com as Habilitações oferecidas nos dois últimos anos, definindo um processo especializado em Pintura, em Escultura, em Gravura ou em Cerâmica. Dessa forma, nos dois primeiros anos se desenvolvia o Desenho Geométrico, o Desenho Técnico, o Desenho Anatômico, o Desenho de Natureza Morta, o Desenho de Paisagem e o Desenho Figurativo, tendo a percepção e a geometria, através da observação e da matemática, como princípio de construção do Desenho.

Verifica-se que, no processo pedagógico do desenvolvimento da formação artística, nessa época e a partir desse currículo da década de 70, o Desenho, em uma concepção acadêmica, é colocado como a forma prioritária e canônica de se apreender e se produzir arte.

Posteriormente, com o crescente desenvolvimento tecnológico do século $\mathrm{XX}$, foram sendo acrescentadas ao currículo novas Habilitações e/ou novas disciplinas de caráter eletivo, principalmente, para dar conta das demandas técnicas e tecnológicas, como a Fotografia e o Vídeo, e, também para acrescentar novos princípios de reflexão, envolvendo a Teoria e a Crítica de Arte. Cumpre salientar que para Santaella (2010) é a fotografia, como um dos muitos meios reprodutores surgidos no desenvolvimento técnico e tecnológico do humano, que deu início ao surgimento de máquinas copiadoras das faculdades cerebrais, levando ao estado da arte atual em termos de hibridização tecnológica em uma Cultura voltada para a técnica e a tecnologia.

É importante ainda reiterar que foi nesse período, na década de 80 , em que ocorreram as reformulações curriculares redefinindo as Habilitações, classificando-as como Bacharelado em Artes Plásticas ou Licenciatura em Educação Artística, essa com uma única Habilitação em Artes Plásticas. Neste período, o eixo de formação artística na estrutura curricular expandida com as tecnologias manteve o Desenho como fundamento, a partir de um princípio construtivo, mas, abarcando também o Desenho Abstrato centrado na abstração geométrica, desenvolvido ainda nos dois primeiros anos do Curso. E, na sequência das transformações, como uma mudança mais efetiva, na estrutura curricular, finalmente, o Desenho se transformou em mais uma Habilitação, desdobrado em Criativo I, II e III, e desenvolvendo-se, principalmente, a partir de um princípio de desconstrução, invertendo a etapa inicial, em consequência da experiência do gesto e da reflexão crítica sobre o processo, encaminhando para a elaboração de um projeto final em Desenho. Também neste período, a Licenciatura em Educação Artística, não sofreu nenhuma reformulação diretamente em sua estrutura curricular, entretanto, percutiu em seu currículo as consequências das mudanças didático-pedagógicas realizadas no Bacharelado, pois ambos constituíam o Curso de Graduação em Artes Plásticas, compartilhando totalmente uma das etapas de desenvolvimento dos Cursos.

É importante ressaltar o hábito dos alunos de permanecer "em curso", solicitando uma ou duas permanências, depois de formados, para retornar ao Curso e complementar o desenvolvimento realizado, cursando uma nova Habilitação, e transformando o Curso em uma prática permanente, totalmente contrária aos processos de institucionalização da Arte.

No início do século XXI, a formação em Artes Visuais substituiu a formação em Artes Plásticas, nomenclatura que foi definida na legislação, determinando uma Formação Superior técnica e tecnológica, ao incluir as novas mídias, envolvendo os laboratórios de multimídia e de fotografia, além dos tradicionais atelieres e oficinas, aos quais se acrescentou os atelieres de História, Teoria e Crítica de Arte e os Laboratórios de Texto e de Museografia.

Revista Digital do LAV - Santa Maria - vol. 8, n. 2, p. 104 - 117. - mai./ago. 2015 ISSN 1983 - 7348 http://dx.doi.org/10.5902/1983734819867 
Esta formação em Artes Visuais foi implementada para dar conta de uma área de conhecimento que deixava de ser considerada somente uma atividade concentrada na transformação da matéria real, através do exercício da forma e da apropriação de um instrumental, e passava a ser considerada também participante da ordem da cognição, envolvendo a reflexão e a conceituação, além de se voltar para um universo virtual, centrado na transformação da imagem.

A partir de 2006, a arquitetura curricular envolvida no Curso de Graduação em Artes Visuais passa a articular os dois currículos, do Bacharelado e da Licenciatura, mantendoos independentes, sendo que, ambos possibilitam a formação especialista e/ou a formação generalista, a partir da autonomia de escolha do aluno, que seleciona as disciplinas que quer fazer durante o desenvolvimento do curso, acarretando históricos acadêmicos distintos em um mesmo Curso de formação, assemelhando-se ao novo modelo emergente da pós-graduação em Cursos de Mestrado e Doutorado em Artes Visuais.

Nesta nova estrutura curricular, o Desenho "muda" de lugar, passando a representar uma área artística e posicionando-se ao lado das demais áreas artísticas. Dessa forma, a construção do conhecimento da Arte e da Arte Educação passa a se distribuir transversalmente entre as oito áreas artísticas e a área da Educação das Artes, já no primeiro e segundo semestre do curso, definindo novos fundamentos e alterando os percursos didáticos de cada uma das áreas.

Metaforicamente, pode-se dizer que, no início do curso, o aluno veste uma espécie de "colete de força" feito de disciplinas que aparentemente são "amarradas" ao início do curso para Ihe possibilitar experiências de aprendizagem que abracem todas as áreas artísticas, além de se estender à inserção de experiências educativas através das Artes Visuais, 0 que faz com que, necessariamente, a contiguidade das disciplinas seja percebida, pois o aluno é levado a encontrar algumas passagens entre elas, transportando o conteúdo de uma para a outra de uma forma, aparentemente, natural, a qual é compreendida como uma construção autoral, ou, como raiz da autonomia necessária ao desenvolvimento de sua formação.

Essa nova realidade é reflexo de uma nova sociedade em que o conhecimento é complexo e a informação está disponível a todos, necessitando, constantemente, que se esteja a fazer escolhas. Caracterizada por integrar dimensões da racionalidade até então separadas, na realidade atual verifica-se um intenso intercâmbio entre a ciência e a arte, assinalando uma mudança no lugar da arte, que tradicionalmente tem lutado contra a desvalorização e segregação que Ihe tem sido imposta, tanto nos processos educacionais, como no campo da pesquisa.

Atualmente, o Curso de Artes Visuais do Instituto de Artes da UFRGS se encontra novamente no foco das mudanças, visando, principalmente, dar conta desse novo sujeito transformado pela cultura atual através de próteses eletrônicas que o empoderam, mas que anulam a sua capacidade de busca e de crítica, tendo em vista que, talvez, ainda não se tenha elaborado a consciência desse novo corpo que está sendo formado nesta mistura, articulada a esse novo lugar que o coloca como sujeito da linguagem.

\section{Da mudança como Aprendizagem}

Fazer parte do corpo docente do Instituto de Artes da UFRGS, e atuar na formação de artistas e professores de arte, especificamente na área de Desenho e Fundamentos da Linguagem Visual, tendo vivido as constantes transformações que tem ocorrido no mundo

Revista Digital do LAV - Santa Maria - vol. 8, n. 2, p. 104 - 117. - mai./ago. 2015 ISSN 1983 - 7348 http://dx.doi.org/10.5902/1983734819867 
da Arte, mas também as transformações que tem ocorrido no processo de institucionalização da Arte na sociedade brasileira, a partir de sua definição como Área de Conhecimento, possibilita uma experiência concreta dos processos de aprendizagem da Arte, acompanhada de uma reflexão sobre os diversos percursos didáticos que tem sido implementados, principalmente, no enfrentamento das mudanças mais radicais dos projetos dos cursos.

Dessa forma, ao desenvolver um percurso de pesquisa estritamente relacionado aos processos de mudança e as mudanças, efetivamente implementadas nos processos pedagógicos de formação próprios da área de Artes, especificamente, da área de Artes Visuais, com o foco na didática do Desenho, muitas questões podem ser levantadas, sendo que algumas são respondidas no próprio processo de formação e no desenvolvimento da linguagem que acompanha o processo, tornando possível a inserção crítica do aluno em algum tipo de mudança operada na atualidade.

De outro modo, verifica-se que as mudanças não são privilégio de nossa época, pois as mudanças sempre ocorreram no mundo, em processos em que se articulam à permanência, podendo assim ser observadas a partir de um horizonte conhecido. O próprio processo de aprendizagem é sempre fruto de uma mudança, em que se reconfigura a cada vez uma nova visão de mundo.

Em 1970 para desenvolver um processo gráfico próprio, e conquistar uma habilidade no Desenho, em um processo pedagógico tradicional, era necessário confrontar-se com um horizonte fixo, inalterável, pois era colocado como um universo canônico a ser alcançado. A aprendizagem era construída através de constantes tentativas de aproximação a esse universo, visto como uma diferença ideal. Nesse desenvolvimento, ocorria um descarte reiterado através de tentativas de acertos e erros, em que os erros eram eliminados como se fossem externos ao próprio processo. Dessa forma, a descoberta de si mesmo como um sujeito criador dava-se por acaso, como um desvio da norma acadêmica, que se repetia sem incentivo, até ter a possibilidade de, ao efetivar a sua formação em Arte, obter o reconhecimento de sua especificidade artística, anteriormente negada, mas agora reconhecida em uma nova existência como um artista profissional.

Nesta etapa, o Desenho constituía o eixo do Conhecimento, e era considerado como a mola construtora da Arte. Entretanto, esse status dava-se sem gerar visibilidade para si próprio, ou seja, sem que o Desenho mesmo fosse focalizado em um processo reflexivo. O Desenho, dessa forma, era trabalhado em um processo que ensejava somente um percurso sem retorno, impossibilitando, inclusive qualquer processo reflexivo.

Já em 1980, o mesmo processo gráfico, para ser desenvolvido e apropriado, deveria abarcar os erros como parte do processo em uma aprendizagem cumulativa, construída em errâncias gráficas, construindo uma amplitude horizontal feita de erros e acertos mesclados em um novo universo expressivo, justificado também com a emergência de novos materiais e instrumentos artísticos. Neste período, o Cânone passou a existir para ser desconstruído, pois era reconstruído um desenvolvimento misto do desenho, que, inicialmente, era trabalhado como um meio/mídia, e, posteriormente como um fim em si mesmo, abarcando em seu próprio corpo gráfico elementos plásticos apropriados de outras áreas artísticas.

Com a mudança ocorrida no currículo de formação em Arte em pleno século XXI, ao se desconstruir o Desenho como um Cânone, ele passa a ser desenvolvido ao lado de todas as demais áreas artísticas, entretanto, ainda com uma carga horária maior, talvez como

Revista Digital do LAV - Santa Maria - vol. 8, n. 2, p. 104 - 117. - mai./ago. 2015 ISSN 1983 - 7348 http://dx.doi.org/10.5902/1983734819867 
um resquício de seu papel canônico. Então, nesta extensão atual que ultrapassa as demais disciplinas do currículo, mas estando, simultaneamente, lado-a-lado com todas, espera-se que o Desenho possa gerar um excedente na relação entre o fazer e o pensar. E o seu desenvolvimento dá-se como uma bolha gráfica em que passa a germinar o pensamento crítico completamente articulado ao fazer gráfico-plástico, e a um fazer realizado na linguagem, que se apresenta como abstrato, tendo partido de uma experiência concreta.

Nessa mudança que define o momento atual, a busca que se faz é pelo encontro com a alteridade que também se encontra na complexa identidade que nos constitui na atualidade, pois fica-se voltado a detectar o sujeito criador que vai sendo desenvolvido por cada um, mas dentro de um universo que abarca tudo e a todos, no universo da linguagem, e nesse novo mundo inventado, não mais natural, então busca-se a alteridade que constitui a todos como sujeitos da linguagem.

Passar do universo natural para o universo da cultura é o que está no cerne da sociedade atual, e ainda se está a apreender a viver neste novo lugar correspondente e constituído pela natureza humana. O universo da cultura é o universo do diverso, da alteridade, e essa mesma alteridade constitui os sujeitos complexos que estão aí a percorrer muitos caminhos em busca dos sentidos que Ihes correspondam.

\section{Das formas da experiência}

Da mesma forma, ao pensar nesta relação entre permanência e mudança também se pode, na atualidade, utilizar uma Escola Superior de Artes que abarca a Música, o Teatro e as Artes Visuais como um dispositivo de observação. Com este dispositivo pode-se analisar um outro horizonte de mudanças implementadas contra um plano de fundo que permanece o mesmo.

Nesse sentido, por exemplo, pensar nas mudanças externas que ocorreram na área de Graduação em Música no Instituto de Artes, que, por um lado, tem ampliado o seu oferecimento com a implementação de um Curso de Música Popular, e, por outro, tem ampliado as Habilitações oferecidas com a criação de um Centro de Música Eletrônica, em uma articulação direta com os programas computacionais e a música eletroacústica, pode fornecer dados para anexarmos às transformações que perpassam o Ensino de Arte.

De outra forma, também pode-se anexar as mudanças que ocorreram na área de Graduação em Teatro, que incorporou o Teatro de Rua e a Performance, e, com frequência tem eliminado o texto oral, para evidenciar o texto e o movimento corporal em um sentido que também se apresenta contrário à tradição.

Trazer estas mudanças que vem ocorrendo em áreas de conhecimento contíguas, e que tem sofrido ampliações/restrições semelhantes a partir da inserção das novas tecnologias, e com a ampliação de um universo até agora restrito e ligado a tradições específicas, a partir de um universo popular e invasivo que, perpassa a tudo na atualidade, misturando, coletando e transformando tudo o que se apresenta, pois traz em sua base a própria mistura, pode servir para lançar alguma luz nos processos pedagógicos que se está tentando trazer à tona.

Por um lado, tem-se a mudança no paradigma do Conhecimento operada ainda no século $X X$, em que o conhecimento passa a ser complexo, não se podendo mais aceder a ele, sem a participação mesma do sujeito. Por outro lado, tem-se os processos educativos que,

Revista Digital do LAV - Santa Maria - vol. 8, n. 2, p. 104 - 117. - mai./ago. 2015 ISSN 1983 - 7348 http://dx.doi.org/10.5902/1983734819867 
talvez assumam a função na atualidade de despertar os sujeitos para a sua própria possibilidade de desenvolvimento.

Entrementes, é importante levantar aqui as reflexões que se tem realizado sobre o período em que se vive como um período pós-humano, em que estamos inseridos em complexos processos de conhecimento em que se articula o físico, o biológico, o social e o cultural. E, nesse sentido, recorre-se a Maturana e Varela (1984), trazendo a construção autopoiética do sujeito, que, por sua vez traduz o conhecimento atual como um conhecimento autopoiético.

Em um universo autopoiético a forma de se gerar qualquer movimento é coletiva e dá-se a partir do conceito de perturbação, que faz com que o sujeito recorra a mudança de si próprio, onde vai encontrar algo que, anteriormente não existia, mas que se alicerça em contextos e conhecimentos já apropriados e dispersos, que passam a ressignificar ao engendrar a construção da nova forma.

Apesar da reflexão, que vai sendo realizada de um modo tênue ao enfatizar o que escapa, o que se transforma, em declinações rápidas, ainda dar conta dessas atualizações constantes, internas e contíguas, todas pressupostas pelas mudanças constitutivas da forma e pelas mudanças tecnológicas, passando do técnico ao operacional, dos produtos aos processos, dos objetos aos sujeitos, fica-se a imaginar como pode ser pensado e desenvolvido o Conhecimento da Arte hoje, a partir das especificidades da Linguagem do Desenho na atualidade, ao ser colocado em diálogo com as transformações operadas no mundo e na Arte Contemporânea.

Será que ainda pode ser significativo trabalhar um elenco de gêneros artísticos dentro do desenvolvimento gráfico dos alunos?

Será que é possível mudar o foco único, modelado como um olho mecânico, que até agora tem construído uma única visão de mundo completamente centrada, eliminando a visão periférica que também corresponde ao humano, para vir a abarcar uma visão estereoscópica, correspondente à coordenação dos dois olhos definidores da anatomia do humano, desdobrando-os em trocas significativas entre uma visão central e uma visão periférica, e abarcando uma nova visão de mundo?

Será que é possível aliar às mudanças atuais à mudança do próprio foco da Educação, centrando-o em um processo relacional, capturado na passagem de um processo estático para um processo dinâmico?

Presentificar uma densidade inicial, partindo da complexidade do Conhecimento e do mundo em que se está inserido, que se apresenta como uma espécie de "escaninho" único, mas multiplicado interiormente, ilimitado e, aparentemente, sempre à disposição, pode levar a sucumbência, não resistindo a acumulação e à necessidade de ficar somente a se elaborar listas.

Todavia, se estas listas forem realizadas a partir de um diálogo entre contextos históricos e contextos discursivos elaborados a partir de experiências concretas de aprendizagem, e contiverem breves percursos didáticos, que possam ser utilizados em distintos conjuntos, a partir de novos e distintos contextos, em misturas que incluem também a interdisciplinaridade, talvez, nessa disponibilidade de listas que contém mínimos/ complexos, quem sabe, pode-se ainda apontar alguns caminhos nas questões que vão sendo levantadas.

Revista Digital do LAV - Santa Maria - vol. 8, n. 2, p. 104 - 117. - mai./ago. 2015 ISSN 1983 - 7348 http://dx.doi.org/10.5902/1983734819867 
Dentre essas questões ressalta-se as seguintes:

O que muda na Arte com as mudanças operadas no mundo atual?

O mundo em que se vive mudou, ou melhor, a realidade construída pelos seres humanos mudou. Hoje vive-se preso a um universo virtual que promete uma conexão global. E ao se efetuar a conexão global pode-se acessar o que se está inserindo nesse universo virtual em qualquer parte do mundo.

E a Arte, como se mostra nesse universo virtual? O que se quer mostrar da Arte nesse universo? A Arte se esconde ao fazer parte da própria maneira desse universo virtual se mostrar?

Por certo que a Arte passou a fazer parte da ordem do discurso, ao ser inserida na Linguagem, e isso se apresenta de uma forma muito clara na Arte Contemporânea, mas, verifica-se que, nesse deslocamento, a Arte ainda encerra a complexidade inerente à ordem da forma na atualidade.

Frente a essa mudança que, de certa maneira, faz da Arte uma peregrina, afastando-a da forma, perpassada pela ideia de viagem, e impregnada por gráficos e mapas, como podese pensar no que muda na didática do Desenho com as mudanças operadas na Arte atual? $\mathrm{E}$, aliado a isso, o que muda no Desenho com as mudanças operadas nos processos educativos atuais?

$E$, ainda, fechando um ciclo de questões que envolvem as mudanças, começando com a mudança da Arte, chega-se a Educação necessária ao mundo atual em que se questiona sobre: Quais são as formas da experiência necessárias ao propósito da Educação atual?

\section{Das formas de acesso que definem a experiência}

Acessar a experiência da Arte a partir da fragilidade das mudanças e deslocamentos pode ser também uma estratégia que leva a construir um percurso didático de Desenho, ao se traçar a convergência de um fluxo de conteúdos através de distintos suportes tradicionais e tecnológicos em processos essencialmente cooperativos.

Pensar, por exemplo, em um percurso possível, pode ser trazer o universo gráfico-plástico do Desenho para uma construção, aparentemente tradicional do autorretrato, entretanto, construída a partir da alteridade presente na linguagem, em articulação de imagens distintas, presentes em discursos e em diversas formas da visibilidade.

Desse novo lugar, a construção de significados passa a ser dada a partir de participações múltiplas que são definidas em cruzamentos, que podem resultar em fragmentos transformados e reapropriados individualmente, ou em formas deformadas, não mais somente pelo retorno da imagem refletida pelo espelho, mas sim pelo retorno da apropriação feita a partir do olhar do outro. Dessa forma, cada sujeito constitui-se e se transforma em um palco discursivo que é submetido a um fluxo de apropriações gráficas, que constituem a sua imagem a partir de um ponto de vista único, reiterado por cada um dos participantes do curso, em desenhos completamente distintos a partir de um mesmo referente.

Parte-se de uma apresentação, realizada em uma organização do espaço físico em forma de círculo, em que todos veem todos, mas a partir de um ângulo que vai se diferenciando a esquerda e a direita, até definir uma visão frontal daquele que está exatamente na frente do que está se apresentando no momento.

Revista Digital do LAV - Santa Maria - vol. 8, n. 2, p. 104 - 117. - mai./ago. 2015 ISSN 1983 - 7348 http://dx.doi.org/10.5902/1983734819867 
Em um grupo de doze alunos, cada um recebe onze papéis transparentes, tamanho A4, e canetas permanentes com uma ponta fina de um lado e uma ponta grossa de outro, para possibilitar tipos distintos de linhas na construção da experiência do desenho.

A solicitação é que cada um realize um desenho do colega durante o momento da apresentação deste, e que focalize, principalmente, a cabeça do apresentador, caracterizando as transformações e perspectivas da face durante o seu discurso, e que utilize todo o espaço da folha A4, pois, este tamanho possibilita um desenho próximo ao tamanho natural, sem esquecer que devem ser priorizadas as deformações correspondentes ao seu próprio ângulo de visão.

O discurso de cada apresentador a ser desenhado ocorrerá no tempo correspondente às respostas das seguintes perguntas, devendo corresponder totalmente ao desenvolvimento do desenho que está sendo realizado:

1. O apresentador se apresenta dizendo o seu nome, complementando com a declaração de alguma coisa que gosta de fazer em seu cotidiano, e que tenha ligação com o que entende por Arte;

2. O apresentador se descreve como se estivesse lendo em seu passaporte, por exemplo, as suas características físicas, como tipo de rosto, cor dos olhos, cor e tipo de cabelos, orelhas, nariz, boca, testa, queixo, enfim, o apresentador vai pensar e descrever os detalhes que o identificam e constituem a sua imagem atual;

3. O apresentador escolhe um acessório, ou um enfeite, que considera como significativo à construção de sua imagem pública, ou seja, a imagem que tem mostrado para os outros, seja na realidade ligada a vida real ou na realidade virtual, e a seguir vai descrever a si mesmo a partir do uso deste acessório.

O trabalho inicia com o primeiro discurso em uma primeira apresentação em que, simultaneamente, todo o grupo é envolvido, pois quem não está se apresentando, está desenhando. E assim continua até cada aluno construir um conjunto de onze desenhos, sendo cada um realizado a partir de um dos apresentadores. Além, é claro de cada participante em algum momento constituir seu próprio palco de apresentação para ser desenhado pelos demais.

Na segunda etapa se modifica o meio, e faz-se uma sessão de fotografias, em que se fotografa cada um dos participantes, como um retrato de um lambe-lambe, mas com o conjunto de transparências com os desenhos sobrepostos colocados como um layer, como uma camada gráfica colocada na frente da face de cada um, compondo com imagem de cada um, e, de certa forma, simultaneamente, obstruindo a definição clara da visão da imagem do retratado.

Na realidade, a imagem fotográfica resultante desse conjunto não elimina a imagem de cada um, mas deixa-a muito próxima de um desenho adensado com linhas e massas ao fundo, assemelhando a imagem resultante à obra de alguns artistas que trabalharam com adensamentos, como, por exemplo Alberto Giacometti (1901-1966), em uma articulação que traz elementos do grafismo erudito e também do primitivo concorrendo na construção do desenho.

Na terceira etapa, muda-se novamente o meio, para que cada um comece a construir o seu próprio adensamento, em um autorretrato que tem como referência a visão que o outro tem de si, percebendo que algumas imagens estão mais próximas e outras mais afastadas, a densidade, articulando desenho e foto na imagem fotográfica, e, ainda, a sua imagem capturada com uma nova transparência colocada sobre um espelho.

Revista Digital do LAV - Santa Maria - vol. 8, n. 2, p. 104 - 117. - mai./ago. 2015 ISSN 1983 - 7348 http://dx.doi.org/10.5902/1983734819867 
As mídias tradicionais do desenho são aqui recuperadas em uma série que passa pela tinta fluída e pincel, até os diferentes grafites em pasta, lápis e barra. Também se desdobra em cor com uma série de materiais secos, desdobrados em pastéis coloridos e carvão sobre papel branco e papel fantasia, perpassando pela tradição do Desenho, pelo traçado primitivo e pela atualidade da mistura.

Pode-se chegar até a animação quadro-a-quadro, de um autorretrato que recupera o discurso inicial, recuperando o movimento, tendo como referência os videoretratos de Robert Wilson (1941- ), ou mesmo, os retratos narrados de Willian Kentridge, em palimpsestos como desenhos (1955-).

Na proposta pedagógica que perpassa o percurso didático descrito, considera-se que tanto o processo como o produto são significativos ao todo e ambos devem ser fruto de reflexão. A visão de mundo que perpassa o percurso didático é um reflexo do mundo contemporâneo, múltiplo e complexo, em que todos se movimentam em distintas realidades, mas sempre a fazer escolhas constantemente. Na proposta está-se a se apropriar de diversos tipos de desenhos e universos gráficos criados, refletindo sobre a forma como se pode fazer a leitura de cada um.

Durante todo o desenvolvimento do trabalho, está sendo proposto o deslocamento entre a linguagem e a metalinguagem do Desenho, envolvendo as diferentes mídias, suportes, instrumentos, equipamentos, e, simultaneamente, fazendo a crítica das estratégias que se utiliza para a elaboração de algum resultado, quer seja expressivo, formal, cognitivo ou lógico-matemático, envolvendo a ordem do discurso e a ordem da forma, em visibilidades ou visualidades construídas e desconstruídas simultaneamente como uma forma de construção.

Para finalizar, recupera-se a afirmação de Santaella (2010) que afirma que se vive hoje em uma "ecologia pluralista da comunicação e da cultura", em uma cultura do computador, em que os dispositivos estão cada vez mais inteligentes e as interfaces com os humanos estão cada vez mais sutis e imperceptíveis. $E$, nesse sentido, também se encerra convocando a urgência da Educação de se posicionar para mostrar o que é possível fazer nessa sociedade, em uma sociedade que prima pela abundância de informação e com frequência tem desperdiçado a cognição advinda dessa informação. Em que se tem muitos excedentes cognitivos que podem ser trabalhados em processos educativos a partir de convergências que se manifestam como processo, mas que possibilitam trazer à tona uma diversidade que pode fazer jus ao universo multidimensional que está a ser preconizado na atualidade.

\section{Referências}

Brasil. Diretrizes Curriculares Nacionais da Área de Artes Visuais. Resolução No1, de 16 de janeiro de 2009. Ministério da Educação, Conselho Nacional de Educação, Câmara Superior de Educação, Brasília:2009.

Brasil. Senado Federal. Lei de Diretrizes e Bases de 1971. Lei n05.692, de 11 de Agosto de 1971. Fixa as diretrizes e bases para o ensino de $1^{\circ}$ e $2^{\circ}$ graus, e dá outras providências. Brasília: 1971.

Brasil. Lei de Diretrizes e Bases da Educação Nacional: lei no 9.394, de 20 de dezembro de 1996, que estabelece as diretrizes e bases da educação nacional. - 5. ed. Brasília: Câmara dos Deputados, Coordenação Edições Câmara, 2010.

Revista Digital do LAV - Santa Maria - vol. 8, n. 2, p. 104 - 117. - mai./ago. 2015 ISSN 1983 - 7348 http://dx.doi.org/10.5902/1983734819867 
Barreto, Umbelina. Espiando pelo buraco da fechadura: O conhecimento de Artes Visuais em nova chave. Tese de Doutorado defendida no Programa de Pós-Graduação em Educação da Faculdade de Educação da Universidade Federal do Rio Grande do Sul. Porto Alegre: 2008.

Maturana, Humberto; Varela, Francisco. El Árbol Del Conocimiento. Santiago: Universitária, 1984.

Santaella, Lucia. A ecologia pluralista da comunicação. Conectividade, mobilidade, ubiquidade. São Paulo: Paulus, 2010.

Wick, Rainer. Pedagogia da Bauhaus. São Paulo: Martins Fontes, 1989.

' Professora Adjunta, nível IV, do Instituto de Artes da Universidade Federal do Rio Grande do Sul. É membro do Grupo de Pesquisa em Educação e Arte (GEARTE) ligado ao PPGEDU da Faculdade de Educação da UFRGS. Possui experiência na área de Artes Visuais, com ênfase em Desenho e Pintura, e tem realizado produção regular em poéticas visuais, além de exposições bienais. Na pesquisa tem atuado, principalmente, nos seguintes temas: Ensino e Pesquisa da Linguagem do Desenho, Pesquisa da Linguagem da Pintura e Ensino e Pesquisa em Semiótica Discursiva. Tem atuado na Educação à distância, desenvolve pesquisa relacionada a Estudos Curriculares de Cursos de Formação em Artes Visuais, Graduação e Pós-Graduação, tendo participado da elaboração do Projeto Pedagógico de Curso de Artes Visuais da UFRGS e coordenado a elaboração do Projeto Pedagógico de Licenciatura em Artes Visuais modalidade à distância da UFRGS - REGESD - PROLICEN 2. Atualmente é Coordenadora da Coordenadoria das Licenciaturas da UFRGS. E.mail: umdb@terra.com.br

Recebido em: 12 de abril de 2015.

Aprovado em: 28 de agosto de 2015.

Revista Digital do LAV - Santa Maria - vol. 8, n. 2, p. 104 - 117. - mai./ago. 2015 ISSN 1983 - 7348 http://dx.doi.org/10.5902/1983734819867 